\title{
Modulatory activities of Agelanthus dodoneifolius (Loranthaceae) extracts on stimulated equine neutrophils and myeloperoxidase activity
}

\author{
RAÏNATOU BOLY ${ }^{1,2}$, STÉPHANIE DESSY ${ }^{3}$, STEPHAN KOHNEN $^{3}$, FÉLIX KINI $^{2}$, MARIUS LOMPO $^{2}$, \\ ANGE MOUITHYS-MICKALAD ${ }^{4}$, INNOCENT PIERRE GUISSOU ${ }^{5}$, JACQUES DUBOIS ${ }^{1}$, \\ GINETTE DEBY-DUPONT ${ }^{4}$, DIDIER SERTEYN ${ }^{4,6}$ and THIERRY FRANCK ${ }^{4,6}$
}

\begin{abstract}
${ }^{1}$ Laboratory of Bioanalytical Chemistry, Toxicology and Applied Physical Chemistry, Institute of Pharmacy, Free University of Brussels, Campus de la Plaine, CP 205/01, Boulevard du Triomphe, 1050 Brussels, Belgium; ${ }^{2}$ Institute for Research in Health Sciences (IRSS/CNRST), BP 7192, Ouagadougou, Burkina Faso; ${ }^{3}$ Celabor SCRL, Avenue du Parc 38, 4650 Herve; ${ }^{4}$ Oxygen Center, Research and Development (CORD), Institute of Chemistry B6a, University of Liege,

Sart Tilman, BE-4000 Liege, Belgium; ${ }^{5}$ Laboratory of Pharmacology, Faculty of Health Sciences (UFR/SDS), University of Ouagadougou, 03 BP 7021, Ouagadougou, Burkina Faso; ${ }^{6}$ Department of General Anaesthesia and Surgical Pathology of Large Animal, Faculty of Veterinary Medicine, B41, University of Liege, Sart Tilman, BE-4000 Liege, Belgium
\end{abstract}

Received September 14, 2010; Accepted November 1, 2010

DOI: $10.3892 / \mathrm{ijmm} .2011 .695$

\begin{abstract}
Agelanthus dodoneifolius DC Danser (Loranthaceae) is used for the treatment of various diseases including asthma. The aqueous and hydroalcoholic extracts have been reported to have anti-inflammatory, spasmolytic and bronchorelaxant activities. The present study investigates the effects of the aqueous decoction and the diethyl ether, ethyl acetate and butanolic fractions of Agelanthus dodoneifolius DC Danser (Loranthaceae) on reactive oxygen species (ROS) production and myeloperoxidase (MPO) release by phorbol 12-myristate 13-acetate (PMA)-stimulated equine neutrophils and on purified equine MPO activity. ROS production and MPO release by the PMA-stimulated neutrophils were measured by
\end{abstract}

Correspondence to: Dr Raïnatou Boly, Laboratory of Bioanalytical Chemistry, Toxicology and Applied Physical Chemistry, Institute of Pharmacy, Free University of Brussels, Campus de la Plaine, CP 205/01, Boulevard du Triomphe, B-1050 Brussels, Belgium E-mail: rainboly@ulb.ac.be

Dr Thierry Franck, Oxygen Center, Research and Development (CORD), Institute of Chemistry B6a, University of Liege, Sart Tilman, BE-4000 Liege, Belgium

E-mail: t.franck@ulg.ac.be

Abbreviations: PMNs, polymorphonuclear neutrophils; MPO, myeloperoxidase; ROS, reactive oxygen species; PMA, phorbol 12-myristate 13-acetate; SIEFED, specific immunological extraction followed by enzymatic detection; $\mathrm{PKC}$, protein kinase $\mathrm{C}$

Key words: Agelanthus dodoneifolius (Loranthaceae), equine myeloperoxidase, SIEFED, chemiluminescence, neutrophils the lucigenin-enhanced chemiluminescence and ELISA assays, respectively. Specific immunological extraction followed by enzymatic detection (SIEFED) was used to specifically measure the equine MPO activity. Identification and quantification of the individual and total phenolic and flavonoid compounds were performed using UPLC-MS/MS equipment and colorimetric methods involving Folin-Ciocalteu and $\mathrm{AlCl}_{3}$, respectively. All the tested extracts displayed dose-dependent inhibitory effects on the oxidant activities of neutrophils; a stronger effect was observed with the organic fractions than the aqueous decoction. These findings could be correlated with a high content of phenolic and flavonoid compounds. The results confirm the previously shown anti-inflammatory effect of Agelanthus dodoneifolius and its potential use for the treatment of neutrophil-dependent inflammatory diseases.

\section{Introduction}

Polymorphonuclear neutrophils (PMNs) are the primary effector cells in host responses to injury and infection (1-4). The antimicrobial function of stimulated PMNs is based on their phagocytic capacity and their ability to release oxidant and proteolytic enzymes as well as reactive oxygen species (ROS) involved in the destruction of microorganisms. ROS play important roles in the pathogenesis of various serious diseases, such as neurodegenerative disorders, aging, cancer, cataracts, inflammation and cardiovascular diseases including atherosclerosis $(5,6)$.

Myeloperoxidase (MPO), a heme peroxidase enzyme stored in the azurophilic granules of neutrophils, plays a crucial role in the destruction of bacteria inside PMNs. The bacterial killing process mainly uses hydrogen peroxide $\left(\mathrm{H}_{2} \mathrm{O}_{2}\right)$ and the chloride anion $\left(\mathrm{Cl}^{-}\right)$to produce hypochlorous 
acid (HOCl), an important microbial killer (4). However, in some conditions involving acute and chronic inflammation, MPO is released from the cells and can cause severe damage to macromolecules in the cell membranes and extracellular space (7). Thus, inhibiting the enzymatic activity of MPO or decreasing the oxidant activity of PMNs may prove beneficial for the treatment of inflammation-related diseases $(8,9)$.

The use of traditional medicine is widespread and plants have long been used in folk medicine for the treatment of chronic inflammatory processes. Agelanthus dodoneifolius (DC) Polhill \& Wiens Danser (Loranthaceae), commonly named Tapinanthus dodoneifolius, is a ubiquitous plant which parasitizes on several plants, including Vitellaria paradoxa (Sapotaceae). This hemi plant parasite has been reported to possess a wide range of medicinal properties $(10,11)$. In the folk medicine of Burkina Faso it is used alone and in association with other traditional remedies for the treatment of various ailments including cardiovascular and respiratory diseases, stomach-ache and wounds.

Preliminary evaluations have reported the spasmolytic and anti-inflammatory activities of the aqueous extract of Agelanthus dodoneifolius. Our research group reported that the aqueous and hydroalcoholic extracts of the plant have effects on the cardiovascular and respiratory systems. Phytochemical screenings of the plant revealed the presence of tannins, anthracenosides, anthraquinones, anthocyanosides, flavonoids, sterols, triterpenes and saponosides. Ouedraogo et al (11) isolated dodoneine from the plant, a dihydropyranone that exhibited a relaxing effect on preconstricted rat aortic rings. It has been suggested that phytochemicals may be responsible for the health benefits of fruits and vegetables $(6,12)$. The anti-inflammatory activity of many plants has been attributed to their high sterol/triterpene and flavonoid content (12). These polyphenolic compounds have been reported to have antioxidant, anti-inflammatory, anti-hepatotoxic and anti-ulcer properties and to be capable of inhibiting the growth of various cancer cell lines (13-15). The antiinflammatory effects of polyphenols result from the inhibition of some key inflammatory enzymes such as cyclooxygenase, lipoxygenase, protein kinase $\mathrm{C}$ (PKC) and phosphoinositide 3-kinase (PI3-kinase) or from the inactivation (or scavenging) of free radicals $(2,12,15-17)$.

Several methods have been developed for extraction and isolation of polyphenols from plant, food or liquid samples. The extraction yield depends on several factors including solvent nature, temperature, $\mathrm{pH}$, part of the plant used, material preparation and the presence of lipophilic compounds. Water and analytical solvents such as methanol, ethanol, diethyl ether, ethyl acetate and butanol have shown a beneficial effect on the yield (18-21).

The aim of the present study was to investigate the ability of the aqueous decoction and the diethyl ether, ethyl acetate and butanol fractions of Agelanthus dodoneifolius to modulate the oxidant activities of isolated neutrophils and myeloperoxidase, two key elements of the inflammatory response. The identification and quantification of some individual polyphenols and the total phenolic and flavonoid contents were assessed by an ultra performance liquid chromatography (UPLC)-MS/MS method and the Folin-Ciocalteu and aluminium chloride $\left(\mathrm{AlCl}_{3}\right)$ colorimetric methods, respectively.

\section{Materials and methods}

Chemicals and reagents. Sodium chloride $(\mathrm{NaCl})$, potassium chloride $(\mathrm{KCl})$, calcium chloride $\left(\mathrm{CaCl}_{2}\right)$, sodium acetate, ammonium acetate, potassium hydroxide, sodium hydroxide, acetic acid, ethanol, $\mathrm{H}_{2} \mathrm{O}_{2}$, dimethyl sulfoxide (DMSO), ethylene diamine tetra-acetic acid disodium salt $\left(\right.$ EDTANa $\left._{2} \mathrm{H}_{2}\right)$, trypan blue, Tween-20, diethyl ether and n-butanol were analytical grade products from Merck (VWRI, Leuven, Belgium). Methanol and ethyl acetate were analytical grade products from Chem-Lab (Zedelgem, Belgium). Paranitrophenyl phosphate, bis-N-methylacridinium nitrate (lucigenin), phorbol 12-myristate 13-acetate (PMA), Percoll, FolinCiocalteu reagent, sodium carbonate, $\mathrm{AlCl}_{3}$, gallic acid, rutin isoquercitrin, and kaempferol were purchased from Sigma (St. Louis, USA). Catechin, chlorogenic acid, coumaric acid, ellagic acid and quercetin were purchased from ChromaDex (LGC Standard, France). Amplex Red was purchased from Molecular Probes (Invitrogen, Merelbeke, Belgium). Bovine serum albumine (BSA) was purchased from Roche (Germany). Deoxygenated MilliQ water or ultrapure water (Easy Pure UV purification system) was used to prepare the solutions.

Plant material. The leaves of Agelanthus dodoneifolius (Loranthaceae) were collected between October and November 2005 from a sheanut tree [Vitellaria paradoxa CF Gaertn (Sapotaceae)] in the region of Ouagadougou and authenticated by Professor I.J. Boussim from the Plant Ecology and Biology Laboratory, Ouagadougou University. A sample specimen was deposited, bearing voucher Nos. 01 and 02 .

Aqueous extraction. The shaded dried leaves of Agelanthus dodoneifolius were ground into a powder before extraction. A decoction was made with the powdered leaves of the plant. A total of $100 \mathrm{~g}$ was brought to boil in 1 liter of distilled water for $15 \mathrm{~min}$. The extract was then filtered, frozen and dried in a freeze dryer (Christ Alpha 1-2 LD).

Organic extraction. Dried and powdered leaves of Agelanthus dodoneifolius $(60 \mathrm{~g})$ were boiled in methanol for $15 \mathrm{~min}$ according to the method of Foungbe et al (19). The extract was dried under reduced pressure. The residue then was resuspended in boiling water $(100 \mathrm{ml})$ and successively exhausted with diethyl ether $(3 \times 100 \mathrm{ml})$, ethyl acetate $(3 \times 100 \mathrm{ml})$ and n-butanol $(3 \times 100 \mathrm{ml})$. Each fraction was dried under reduced pressure and stored in a desiccator for biological assays.

Isolation of equine neutrophils. Neutrophils were isolated from EDTA $(1.6 \mathrm{mg} / \mathrm{ml})$ anticoagulated blood drawn from the jugular vein of healthy horses that were fed and bred in identical conditions and were not subjected to any medical treatment (Faculty of Veterinary Medicine, University of Liege, Belgium). The neutrophils were isolated at room temperature $\left(18-22^{\circ} \mathrm{C}\right)$ by centrifugation $(400 \mathrm{x} \mathrm{g}, 45 \mathrm{~min}$, $20^{\circ} \mathrm{C}$ ) on a discontinuous Percoll density gradient according to the method of Pycock et al (22). The cells were gently collected and washed with 2 volumes of physiological saline solution. The cell pellets were resuspended in $20 \mathrm{mM}$ phosphate-buffered saline (PBS) at $\mathrm{pH} 7.4$ with $137 \mathrm{mM}$ 
$\mathrm{NaCl}$ and $2.7 \mathrm{mM} \mathrm{KCl}$. The cell suspension was more than $90 \%$ of neutrophils and displayed a viability of $>90 \%$ as measured by the trypan blue exclusion test. Each batch of neutrophils was prepared from $90 \mathrm{ml}$ of blood from one horse. The cells were used within $4 \mathrm{~h}$ after isolation, and each standard and extract concentration was tested in triplicate. Each experiment was repeated at least five times with different batches of cells.

Preparation of neutrophil activator and plant extract solution. PMA was dissolved in DMSO and aliquots were kept at $-20^{\circ} \mathrm{C}$. Just prior to use, ultrapure water was added to the aliquots to obtain a stock solution of $16 \mu \mathrm{M}$ PMA with $1 \%$ DMSO. In the assays, PMA was used at the final concentration of $0.8 \mu \mathrm{M}$ and $0.05 \%$ DMSO. For the stimulated neutrophils, parallel assays were also performed with cell suspensions in PBS alone or PBS in $0.05 \%$ DMSO. The aqueous extract was solubilized in ultrapure water to obtain stock solutions of 5 , $2.5,1,0.5,0.25,0.1,0.05$ and $0.01 \mathrm{mg} / \mathrm{ml}$. Dried fractions derived from the diethyl ether, ethyl acetate and n-butanol extractions were solubilized in DMSO (final concentration in any experiment did not exceed $1 \%$ ) to obtain stock solutions of the same concentrations. An adequate volume of these solutions was added to the cell suspensions or in the MPO activity assays to reach final concentrations of 50, 25, 10, 5, $2.5,1,0.5$ and $0.1 \mu \mathrm{g} / \mathrm{ml}$. Gallic acid and quercetin were solubilized in DMSO at final concentrations of $12.8,8.5$, $4.3,1.3,0.9$, and $0.4 \mu \mathrm{g} / \mathrm{ml}$ and $22.7,15.1,7.6,2.3,1.5$, and $0.8 \mu \mathrm{g} / \mathrm{ml}$, respectively.

Measurement of ROS production. The ROS production by activated neutrophils was measured by lucigenin-enhanced chemiluminescence (CL) according to the method adapted from Benbarek et al (23). Lucigenin is commonly used to increase the sensitivity of cellular CL assays. It has been reported to react mainly with superoxide anion $\left(\mathrm{O}_{2}{ }^{-}\right)$which is the first ROS formed by the activation of NADPH oxidase and the first step in the generation of most of the other ROS $(24,25)$. Neutrophil suspensions $\left(10^{6}\right.$ neutrophils/well $)$ were distributed in a 96-well White Combiplate 8 microtiter plate (Thermo Labsystems, Finland) and incubated for $10 \mathrm{~min}$ at $37^{\circ} \mathrm{C}$ with the extract solutions (aqueous extract and organic fractions) of Agelanthus dodoneifolius at the final concentrations of $50,25,10,5,2.5,1,0.5$ and $0.1 \mu \mathrm{g} / \mathrm{ml}$. After the incubation, $25 \mu \mathrm{l}$ of $\mathrm{CaCl}_{2}(10 \mu \mathrm{M}), 2 \mu \mathrm{l}$ of lucigenin $(5 \mu \mathrm{M})$ and, just before CL measurement, $10 \mu \mathrm{l}$ of the $16 \mu \mathrm{M}$ PMA stock solution were added to the cell suspensions. The CL response of the neutrophils was monitored for $30 \mathrm{~min}$ at $37^{\circ} \mathrm{C}$ with a Fluoroskan Ascent FL (Thermo Scientific, Tournai, Belgium) and expressed as the integral value of the total CL emission. The control assay was set as $100 \%$ of the CL response and it was performed with PMA-stimulated neutrophils in the presence of PBS for the aqueous extract and DMSO for the gallic acid, quercetin, diethyl ether, ethyl acetate and n-butanolic fractions.

Measurement of the total amount of MPO released by the activated neutrophils. The neutrophil suspensions $\left(10^{6} \mathrm{cells} / \mathrm{ml}\right)$ were incubated for $10 \mathrm{~min}$ at $37^{\circ} \mathrm{C}$ with the extract solutions of Agelanthus dodoneifolius at the final concentrations of 50 ,
$25,10,5,2.5,1,0.5$ and $0.1 \mu \mathrm{g} / \mathrm{ml}$, and then activated for $30 \mathrm{~min}$ at $37^{\circ} \mathrm{C}$ with PMA (final concentration $=0.8 \mu \mathrm{M}$ ). After activation, the neutrophil suspensions were centrifuged (450 x g, $10 \mathrm{~min}$ ) and the supernatants were collected. The amount of MPO released by the neutrophils was measured in the supernatants by an ELISA assay with antibodies raised against equine MPO (26) and distributed by BiopTis (Liege, Belgium). Briefly, polyclonal antibodies against purified equine MPO were obtained in rabbit and were used to coat 96-well microtiter plates. The supernatants diluted 200-fold were added into the wells and incubated overnight at $4^{\circ} \mathrm{C}$. After washing, a second anti-equine MPO polyclonal antibody raised in a guinea pig and coupled to alkaline phosphatase was added and incubated for $2 \mathrm{~h}$ at $37^{\circ} \mathrm{C}$. After washing, phosphatase activity was measured after $30 \mathrm{~min}$ of incubation $\left(37^{\circ} \mathrm{C}\right.$, in the dark) with a paranitrophenyl phosphate solution. The absorbance (405 $\mathrm{nm}$ ) proportional to the content of MPO was read with the Multiskan Ascent (Thermo Scientific). The control assay was set as $100 \%$ of the MPO release and it was performed with PMA-stimulated neutrophils in the presence of PBS for the aqueous extract and DMSO for the gallic acid, quercetin, diethyl ether, ethyl acetate and n-butanolic fractions.

Measurement of active MPO by the specific immunological extraction followed by enzymatic detection (SIEFED) method. SIEFED is an original method developed for the specific detection of active equine neutrophil MPO (27). The first step is an immunoextraction of MPO from a solution or a biological sample by specific immobilized antibodies. The next step consists of washes to eliminate non-specifically bound compounds or interfering substances. The third step is the detection of MPO enzymatic activity with $\mathrm{H}_{2} \mathrm{O}_{2}$ as the substrate, Amplex Red as the electron donor and nitrite as an enhancer of the reaction. The nitrite ions enhance the peroxidase activity of the enzyme, thereby increasing the amount of Amplex Red molecules transformed into fluorescent molecules. Test solutions at final concentrations of 50, 25, 10, $5,2.5,1,0.5$ and $0.1 \mu \mathrm{g} / \mathrm{ml}$ were incubated for $10 \mathrm{~min}$ with pure equine MPO $(50 \mathrm{ng} / \mathrm{ml})$ in the dilution buffer $(20 \mathrm{mM}$ PBS with $5 \mathrm{~g} /$ liter BSA and $0.1 \%$ Tween-20) before the immunoextraction step. After the incubation, the mixture was loaded onto the SIEFED microplate coated with rabbit polyclonal antibodies $(3 \mu \mathrm{g} / \mathrm{ml})$ against equine MPO and incubated $\left(2 \mathrm{~h}, 37^{\circ} \mathrm{C}\right)$ to capture MPO with the antibodies. After the washing step, the enzymatic activity of MPO was measured without possible interference of the sample medium. The controls were set as $100 \%$ MPO activity and performed with purified MPO in the presence of PBS for the aqueous extract and DMSO for the gallic acid, quercetin, diethyl ether, ethyl acetate and n-butanolic fractions.

UPLC-MS/MS analysis. UPLC is a highly sensitive form of liquid chromatography (LC) in which narrow-bore columns packed with very small particles $(1.7 \mu \mathrm{m})$ and mobile phase delivery systems operating at high back-pressures are used. The analyses were performed on an Acquity UPLC ${ }^{\mathrm{TM}}$ system (Waters, Milford, MA, USA) connected to a photodiode array detector (PDA) and a tandem quadrupole (TQD) mass spectrometer (Waters). The wavelengths in the PDA detector were set at 280, 320 and $360 \mathrm{~nm}$ for hydroxybenzoic acid derivatives, 


\section{A- Phenolic acids}<smiles>O=C(O)c1cc(O)c(O)c(O)c1</smiles>

Gallic acid<smiles>O=C(O)Cc1ccc(O)cc1</smiles>

p-Coumaric acid<smiles>O=C(C=Cc1ccc(O)c(O)c1)OC1C(O)C(O)C(O)CC1(O)C(=O)O</smiles><smiles></smiles>

\section{Ellagic acid}

\section{Chlorogenic acid}

\section{B- Flavonoids}

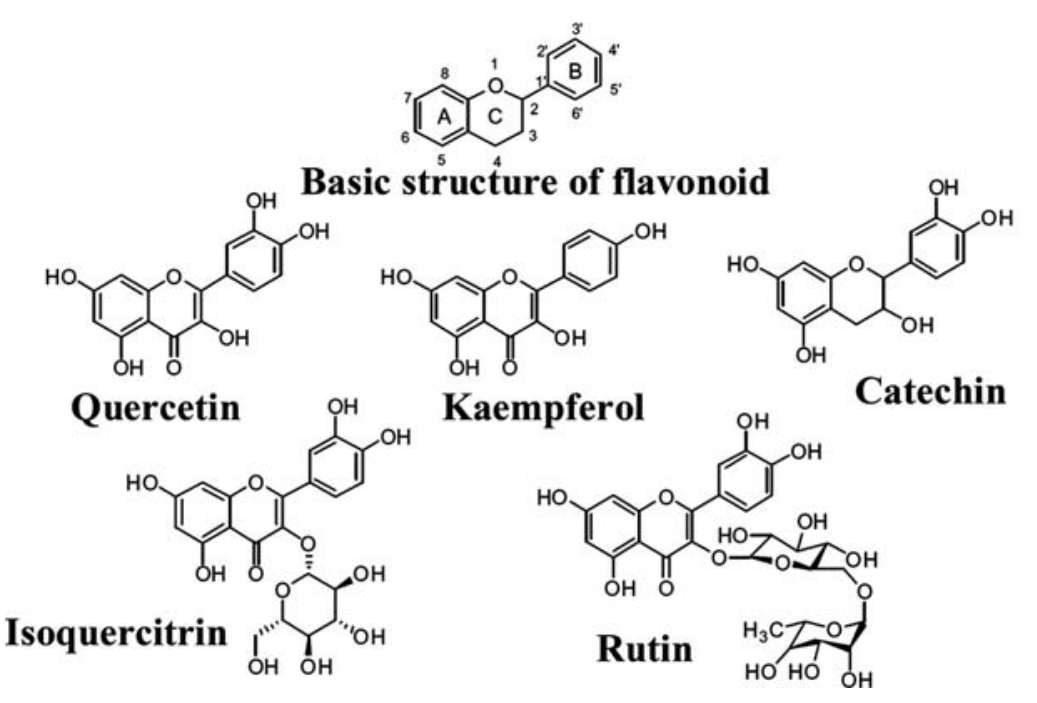

Figure 1. Chemical structures of the identified compounds in Agelanthus dodoneifolius.

hydroxycinnamic acid derivatives and flavonols, respectively. The TQD mass spectrometer was equipped with a Z-spray electrospray ionization (ESI) interface; analyses were performed as a single run in a negative mode. MassLynx ${ }^{\mathrm{TM}}$ software (version 4.0, Waters) was used for instrument control and for data acquisition and processing. The fractions were dissolved in methanol and injected onto an Acquity UPLC ${ }^{\text {TM }}$ BEH Shield RP18 column (2.1x100 mm, $1.7 \mu \mathrm{m}$; Waters). A gradient elution adapted from an HPLC method (28) was developed for analysis. The method was used to determine gallic acid, catechin, chlorogenic acid, coumaric acid, ellagic acid, rutin, quercetin, kaempferol and isoquercitrin content in the fractions. The identification of polyphenols was carried out using their retention times combined with comparisons of the spectroscopic and spectrophotometric data to those of the standards.

Total polyphenol estimation. The total phenolic content was determined according to the Folin-Ciocalteu colorimetric method (29). Each plant extract was prepared at a concentration of $1 \mathrm{mg} / \mathrm{ml}$. An aliquot of plant extract solution $(200 \mu \mathrm{l})$ was mixed with $800 \mu 1$ of Folin-Ciocalteu reagent and $3 \mathrm{ml}$ of water. After vortexing at room temperature, $1.2 \mathrm{ml}$ of
$\mathrm{Na}_{2} \mathrm{CO}_{3}(200 \mathrm{~g} /$ liter $)$ and $4.8 \mathrm{ml}$ of water were added and the mixture was allowed to stand for $2 \mathrm{~h}$ at room temperature. Absorbances were measured at $760 \mathrm{~nm}$ against a water blank. The standard calibration curve was plotted with gallic acid $\left(y=426.47 x+0.0357, R^{2}=0.99\right)$. The results were expressed as grams of gallic acid equivalents per kilogram of sample.

Total flavonoid estimation. Flavonoid content was measured by the $\mathrm{AlCl}_{3}$ colorimetric method according to the DOWD method as adapted by Arvouet-Grand et al (30). The aqueous decoction and the organic fractions were solubilized in water and methanol, respectively, to a final concentration of $1 \mathrm{mg} / \mathrm{ml}$. A total of $2 \mathrm{ml}$ of plant fraction was mixed with $2 \mathrm{ml}$ of a methanolic solution of $\mathrm{AlCl}_{3}(2 \%)$. The absorbance was read at $415 \mathrm{~nm}$ after 10 min against a blank sample containing $2 \mathrm{ml}$ of plant fraction and $2 \mathrm{ml}$ of methanol without $\mathrm{AlCl}_{3}$. Rutin was used to construct the calibration curve $(\mathrm{y}=0.0139 \mathrm{x}$ $0.0202, R^{2}=0.99$ ), and the results were expressed as grams of rutin equivalents per kilogram of sample.

Statistical analysis. In the in vitro experiments with neutrophils or MPO, each point was repeated at least three times, and each experiment was repeated five times with 


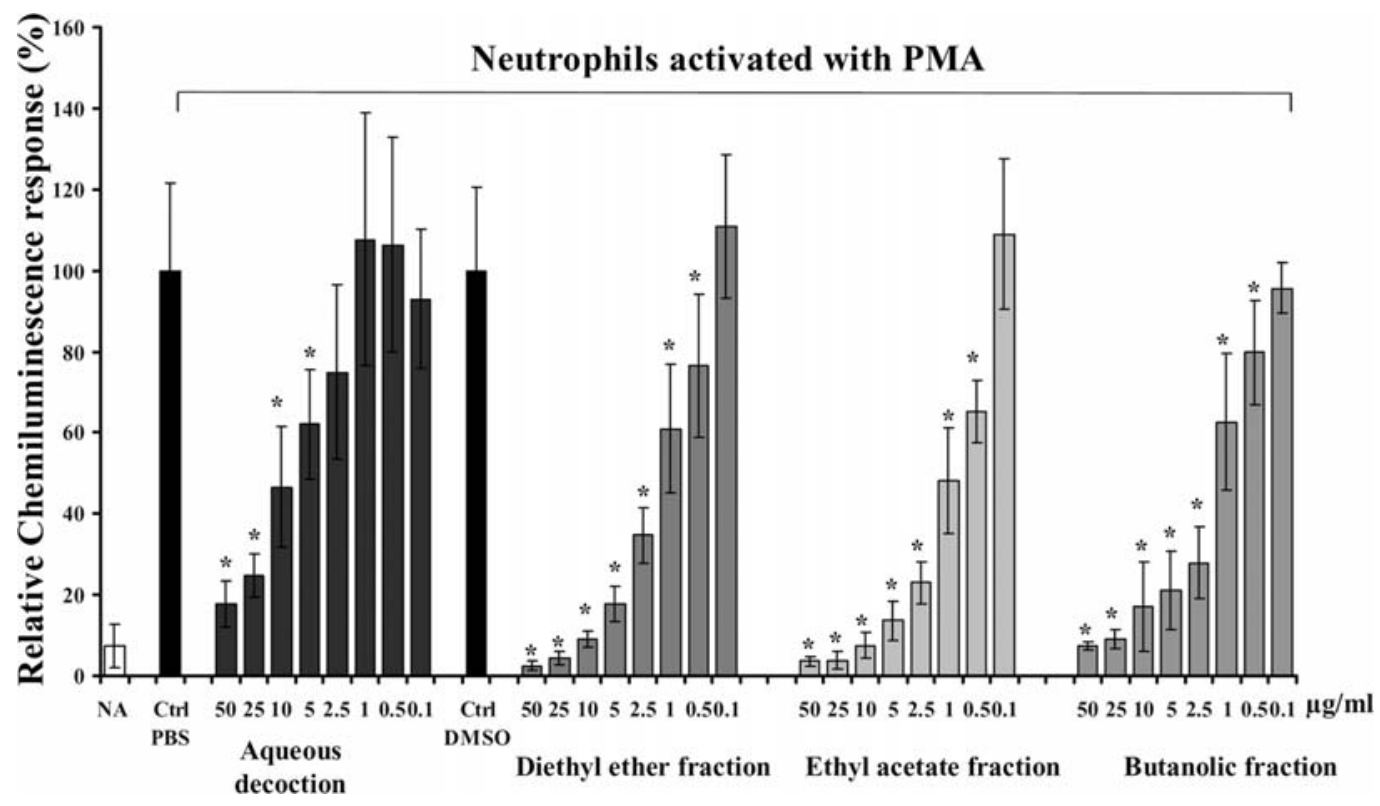

Figure 2. Effect of the aqueous decoction, diethyl ether, ethyl acetate and butanolic fractions of Agelanthus dodoneifolius on the chemiluminescence response produced by PMA-stimulated equine neutrophils. The aqueous decoction was solubilized in water and the organic fractions in DMSO. Cells (10 $6 /$ well) were incubated for $10 \mathrm{~min}$ with tested solutions at concentrations of 50, 25, 10, 5, 2.5, 1, 0.5 and $0.1 \mu \mathrm{g} / \mathrm{ml}$. After $10 \mathrm{~min}$ of incubation, $25 \mu 1$ of CaCl $2(10 \mu \mathrm{M}), 2 \mu 1$ of lucigenin $(5 \mu \mathrm{M})$ and, just before CL measurement, $10 \mu 1$ of PMA (16 $\mu \mathrm{M})$ were added to the cell suspensions. For the no activated cells, $10 \mu 1$ of a $1 \%$ DMSO solution was added to the cell suspension to replace the PMA. A *p-value $<0.05$ (one-way ANOVA followed by Dunnett's post-test) was considered to indicate significance vs. control solutions [Ctrl PBS and Ctrl DMSO which were set as $100 \%$ (mean \pm SD)]. NA, not activated.

batches of cells from different horses or with purified equine MPO. Data expressed as relative values are presented as the mean $\pm \mathrm{SD}$. The $\mathrm{IC}_{50}$ values were estimated by a non-linear regression analysis using the GraphPad Prism (version 3.0) statistical software for Windows (GraphPad Software, San Diego, CA, USA). Statistical analysis was performed using GraphPad Instat 3.05 (GraphPad Software). An unpaired t-test with Welch's correction was used to compare the $\mathrm{IC}_{50}$ values of the extracts in each in vitro test. A one-way ANOVA followed by Dunnett's post-test was performed to compare the inhibitory percentage of the extract with the corresponding controls. A p-value $<0.05$ was considered significant.

\section{Results}

Cell viability. The cell viability was checked by the trypan blue exclusion test and the values were $\geq 90 \%$ for the control and tested solutions at concentrations between 0.1-50 $\mu \mathrm{g} / \mathrm{ml}$, indicating no cytotoxicity towards the neutrophils.

Effect of Agelanthus aqueous extract and organic fractions on the total ROS production of equine stimulated neutrophils. Fig. 2 shows the CL response upon stimulation of equine neutrophils. The ROS production by neutrophils in response to PMA stimulation was decreased in a dose-dependent

Table I. $\mathrm{IC}_{50}$ values of Agelanthus dodoneifolius extracts and reference compounds on ROS production and MPO release by stimulated neutrophils and on MPO activity.

\begin{tabular}{|c|c|c|c|}
\hline \multirow[b]{2}{*}{ Tested compound } & \multicolumn{3}{|c|}{$\mathrm{IC}_{50}(\mu \mathrm{g} / \mathrm{ml})$} \\
\hline & ROS production & MPO release & MPO activity \\
\hline Gallic acid & $0.4 \pm 0.1^{\mathrm{a}}$ & $>25$ & $1.1 \pm 0.2^{\mathrm{a}}$ \\
\hline Quercetin & $2.8 \pm 0.7^{b}$ & $>50$ & $6.3 \pm 0.4^{b}$ \\
\hline \multicolumn{4}{|c|}{ Agelanthus dodoneifolius extracts } \\
\hline Aqueous fraction & $10.4 \pm 2.7^{\mathrm{c}}$ & $13.2 \pm 2.2^{\mathrm{a}}$ & $7.3 \pm 3.7^{\mathrm{b}}$ \\
\hline Diethylether fraction & $1.8 \pm 0.6^{\mathrm{d}, \mathrm{b}}$ & $19.8 \pm 7.2^{\mathrm{a}}$ & $3.7 \pm 1.4^{\mathrm{c}}$ \\
\hline Ethyl acetate fraction & $1.1 \pm 0.7^{\mathrm{d}, \mathrm{a}}$ & $3.9 \pm 1.3^{\mathrm{b}}$ & $2.2 \pm 0.6^{\mathrm{c}}$ \\
\hline Butanolic fraction & $1.6 \pm 0.9^{\mathrm{d}, \mathrm{b}}$ & $2.9 \pm 0.7^{b}$ & $8.5 \pm 2.8^{b}$ \\
\hline
\end{tabular}

Data are expressed as the mean \pm SD ( $n=5$ independent experiments). Values within columns not followed by the same superscript letters are significantly different $(\mathrm{p}<0.05)$ as determined by an unpaired t-test with Welch's correction using GraphPad Instat 3.05. 


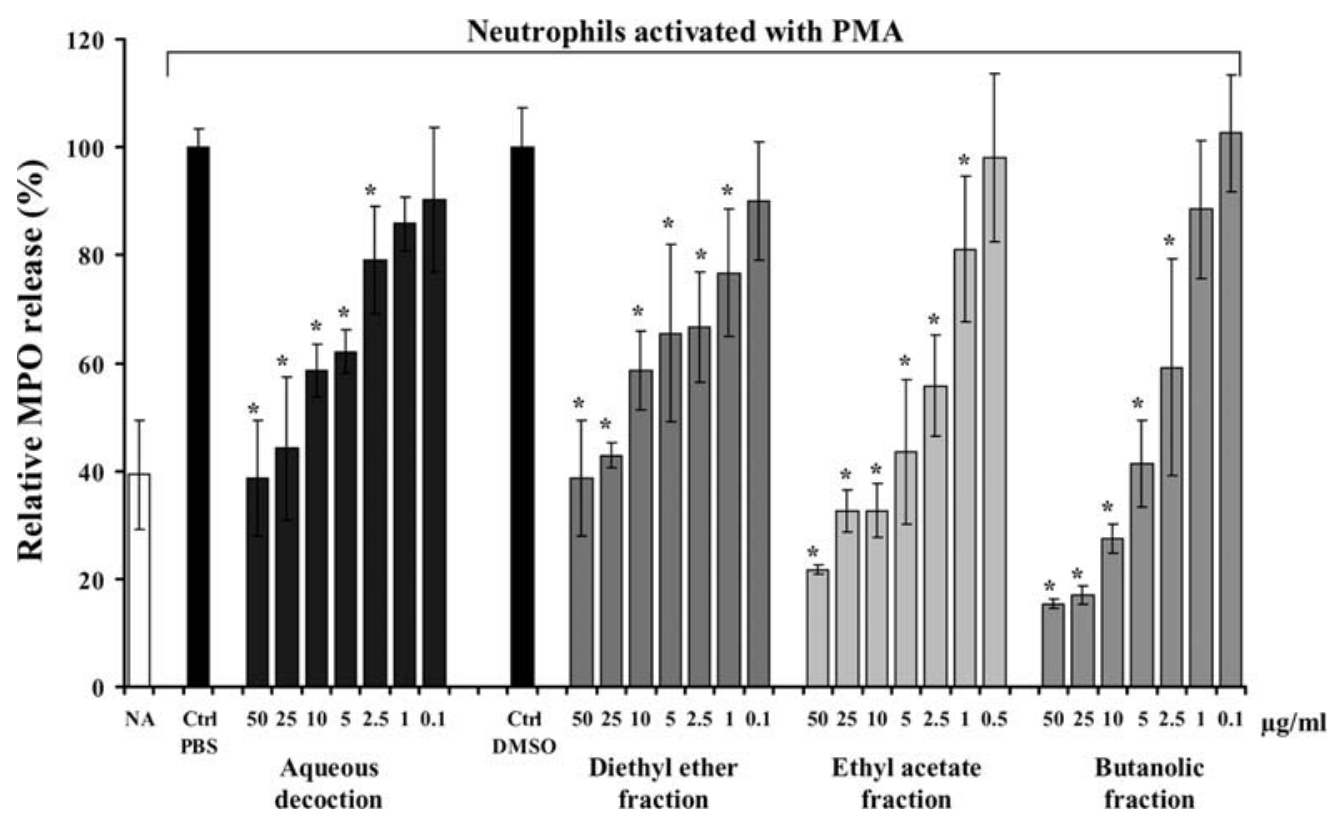

Figure 3. Effect of the aqueous decoction, diethyl ether, ethyl acetate and butanolic fractions of Agelanthus dodoneifolius on MPO release by stimulated neutrophils. The aqueous decoction was solubilized in water and organic fractions in DMSO. The neutrophil suspensions $\left(10^{6} / \mathrm{ml}\right)$ were incubated for $10 \mathrm{~min}$ with tested solutions at concentrations of 50, 25, 10, 5, 2.5, $1,0.5$ and $0.1 \mu \mathrm{g} / \mathrm{ml}$, and then activated for $30 \mathrm{~min}$ at $37^{\circ} \mathrm{C}$ with PMA (final concentration, $8 \times 10^{-7} \mathrm{M}$ ). The amount of MPO released by the neutrophils was measured in the supernatants by an ELISA assay. A * p-value $<0.05$ (one-way ANOVA followed by a Dunnett's post-test) was considered to indicate significance vs. control solutions [Ctrl PBS and Ctrl DMSO which were set as 100\% (mean \pm SD)]. NA, not activated.

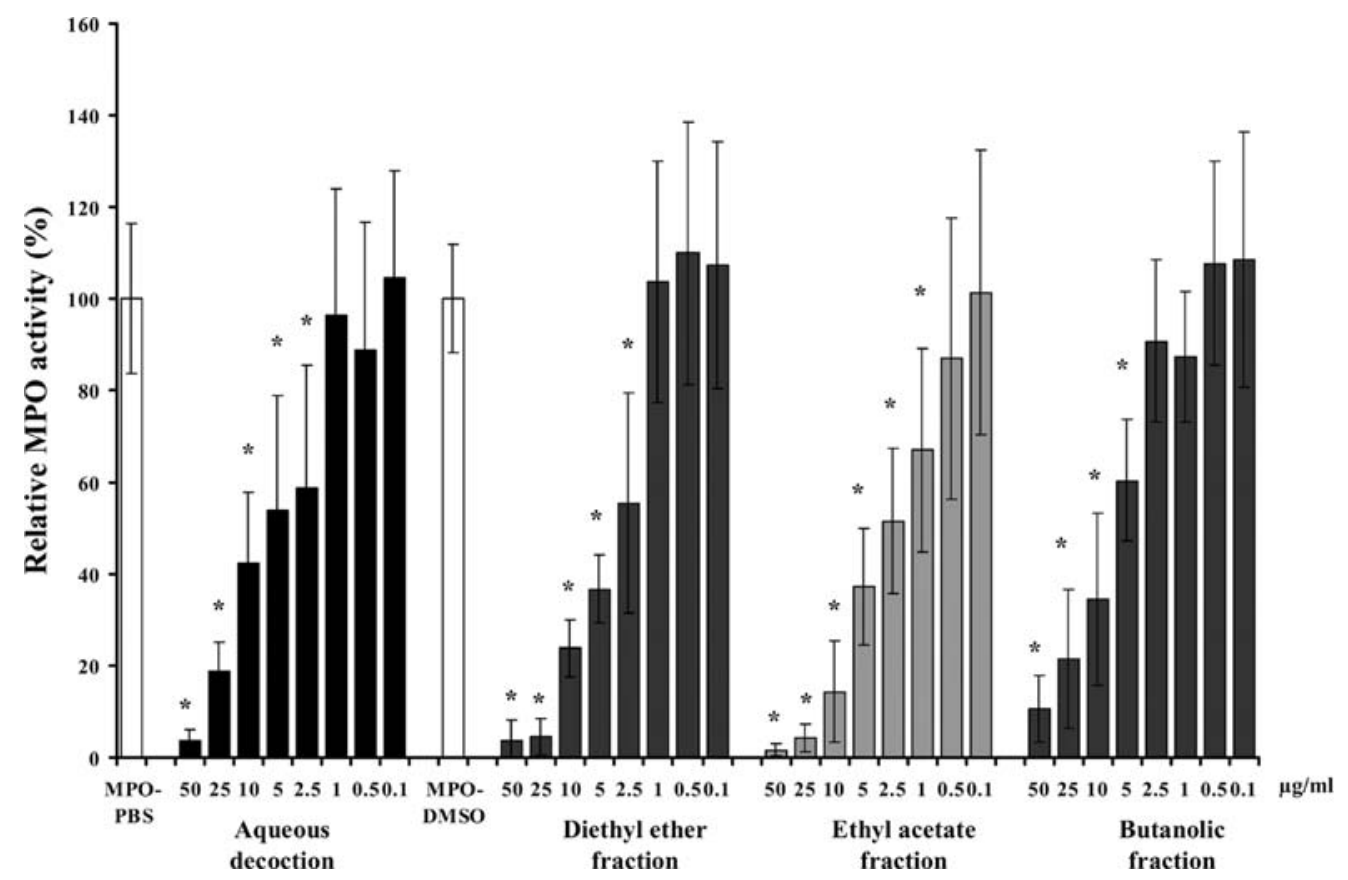

Figure 4. Effect of the aqueous decoction, diethyl ether, ethyl acetate and butanolic fractions of Agelanthus dodoneifolius on the MPO activity measured by SIEFED. The aqueous decoction was solubilized in water and organic fractions in DMSO. Test solutions at final concentrations of 50, 25, 10, 5, 2.5, 1, 0.5 and $0.1 \mu \mathrm{g} / \mathrm{ml}$ were incubated for $10 \mathrm{~min}$ with pure equine MPO $(50 \mathrm{ng} / \mathrm{ml}$ ) before performing SIEFED. A *p-value <0.05 (one-way ANOVA followed by Dunnett's post-test) was considered to indicate significance vs. control solutions [MPO-PBS and MPO-DMSO which were set as 100\% (mean \pm SD)].

manner for all the tested solutions; the inhibitory effect was most noticeable for organic fractions. Interestingly, the $\mathrm{IC}_{50}$ values between organic fractions were statistically similar $(p>0.05)$ and all were significantly different from the $\mathrm{IC}_{50}$ value of the aqueous decoction (Table I). The $\mathrm{IC}_{50}$ of gallic acid $(0.4 \mu \mathrm{g} / \mathrm{ml})$ was significantly lower than those of quercetin $(2.8 \mu \mathrm{g} / \mathrm{ml})$ and all the fractions except for ethyl acetate (Table I). ROS scavenging efficacy of the extracts 
Table II. Quantitative determination of phenolic compounds in the fractions ( $\mathrm{g} / \mathrm{kg}$, dry weight) as determined by the UPLC$\mathrm{MS} / \mathrm{MS}^{\mathrm{a}}$ and spectrophotometric analysis.

\begin{tabular}{lcccc}
\hline Compound & Aqueous decoction & Diethyl ether fraction & Ethyl acetate fraction & Butanolic fraction \\
\hline Gallic acid & 3.5 & 20.7 & 9.5 & 1.1 \\
Catechin & 7.3 & 104.7 & 57.4 & 1.0 \\
Chlorogenic acid & 0.3 & ND & 0.3 & 0.3 \\
Coumaric acid & ND & 2.2 & 1.2 & ND \\
Ellagic acid & ND & 2.9 & 0.5 & ND \\
Rutin & 2.3 & 0.05 & 3.2 & 8.2 \\
Quercetin & ND & 3.1 & 1.9 & ND \\
Kaempferol & ND & 0.8 & 0.4 & ND \\
Isoquercitrine & 0.8 & 3.3 & 6.5 & 0.6 \\
Total polyphenol $^{\mathrm{b}}$ & 212.0 & 528.6 & 32.2 & 388.4 \\
Total flavonoid $^{c}$ & 41.3 & 8.0 & 50.3 \\
\hline
\end{tabular}

${ }^{\mathrm{a}}$ Quantification was performed using external calibration onto an Acquity UPLC ${ }^{\mathrm{TM}}$ BEH Shield RP18 column $(2.1 \times 100 \mathrm{~mm}, 1.7 \mu \mathrm{m}$; Waters). Data recorded were average of two replicates; ND, not detected; ${ }^{b}$ Total polyphenols measured by the Folin Ciocalteu method were expressed in gallic acid equivalent $\left(\mathrm{g} / \mathrm{kg}\right.$ of fraction, dry weight); ${ }^{\mathrm{c}}$ Total flavonoid determined by the aluminium chloride $\left(\mathrm{AlCl}_{3}\right)$ colorimetric method was expressed in rutin equivalent $(\mathrm{g} / \mathrm{kg}$ of fraction, dry weight).

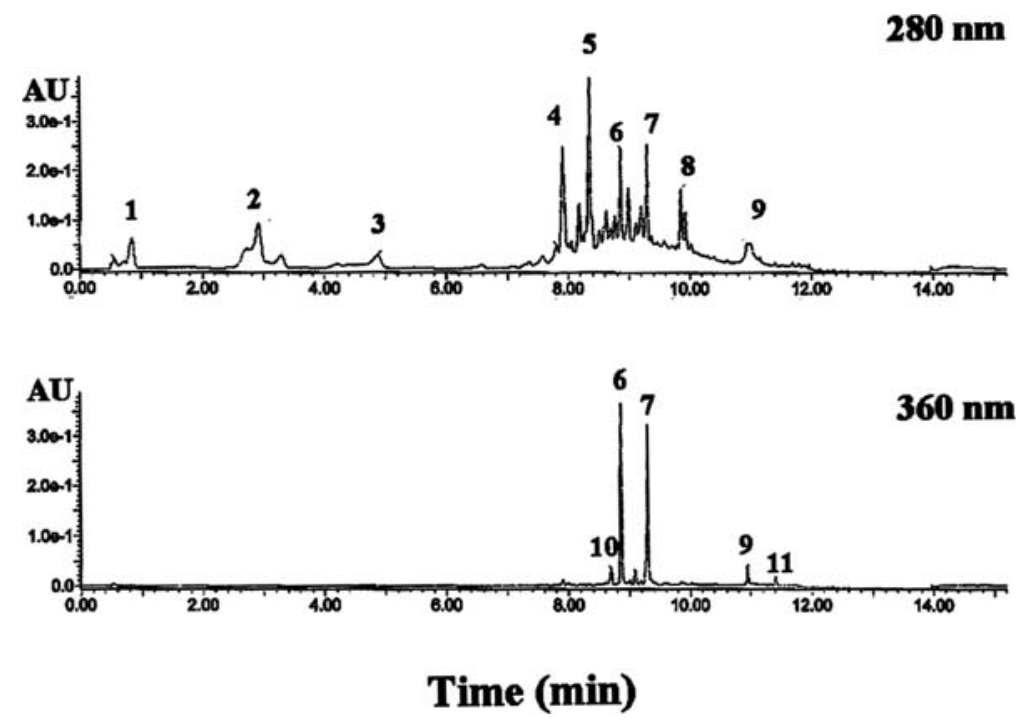

Figure 5. UPLC-UV chromatogram of the ethyl acetate fraction detected at 280 and $360 \mathrm{~nm}$ with the photodiode array detector. The fraction was solubilized in methanol and injected onto an Acquity UPLC ${ }^{\text {TM }}$ BEH Shield RP18 column (2.1x100 mm, $1.7 \mu$ m; Waters). Peak 1, gallic acid; 2, catechin; 3, chlorogenic acid; 4, ferulic acid; 5, unknown; 6, isoquercitrin; 7, unknown; 8, unknown; 9, quercetin; 10, rutin; 11, kaempferol.

and standards decreased in the following order: gallic acid $>$ ethyl acetate fraction $>$ diethyl ether fraction $>$ butanolic fraction $>$ quercetin $>$ aqueous fraction.

Effect of Agelanthus extracts on the total amount of MPO released by activated neutrophils. The results reported in Fig. 3 indicate that all the tested extracts displayed a dosedependent inhibitory effect on the release of MPO. The butanolic and ethyl acetate fractions demonstrated the most efficient inhibition without a significant difference in their $\mathrm{IC}_{50}$ values. The aqueous decoction and diethyl ether fraction were less effective, and no significant difference was observed between them. Quercetin and gallic acid were less efficient than the plant fractions. The extracts and standards exhibited an increasing efficacy in the following order: butanolic fraction $>$ ethyl acetate fraction $>$ aqueous decoction $>$ diethyl ether fraction $>$ gallic acid $>$ quercetin.

Effect of the Agelanthus extracts on the peroxidase activity of MPO. As shown in Fig. 4, all tested extracts displayed a dose-dependent inhibitory effect on MPO activity compared to the control sample. Considering the $\mathrm{IC}_{50}$ values reported in Table I, the ethyl acetate fraction was the most active with regard to the inhibition of MPO activity. The $\mathrm{IC}_{50}$ value of 
gallic acid $(1.1 \mu \mathrm{g} / \mathrm{ml})$ was significantly lower than those of quercetin $(6.3 \mu \mathrm{g} / \mathrm{ml})$ and all the other fractions. The MPO inhibitory activity decreased in the following order: gallic acid $>$ ethyl acetate fraction $>$ diethyl ether fraction $>$ quercetin $>$ aqueous fraction $>$ butanolic fraction.

UPLC-MS/MS analysis. UPLC-MS/MS analyses were performed to identify and quantify the fraction constituents. As shown in Table II, the results indicated that the extracts were rich in phenolic and flavonoid compounds with a high gallic acid and catechin content especially for the diethyl ether and ethyl acetate fractions. No coumaric acid, ellagic acid, quercetin or kaempferol was detected in the aqueous decoction and butanolic fraction, which were mainly characterized by a high rutin content. Quercetin was only detected in the diethyl ether and ethyl acetate fractions. Fig. 5 contains an example of an ethyl acetate fraction chromatogram obtained at 280 and $360 \mathrm{~nm}$. Most of the peaks were identified by comparing them to standard molecules with the exception of three peaks that are still unknown.

Total phenolic and total flavonoid content. For comparison to the UPLC-MS/MS polyphenols quantification, we used spectrophotometric methods to estimate the phenolic and flavonoid content of the plant fractions. The total phenolic content was found to decrease in the following order: ethyl acetate fraction $>$ diethyl ether fraction $>$ butanolic fraction $>$ aqueous decoction. The total flavonoid content was found to decrease in the following order: butanolic fraction $>$ aqueous decoction $>$ ethyl acetate fraction $>$ diethyl ether fraction (Table II).

\section{Discussion}

The antimicrobial function of neutrophils can have some side effects including the induction of an excessive production of ROS that are responsible for a large number of various diseases such as cancer, cardiovascular diseases, and inflammation (31). Thus, the inhibition of neutrophil migration may account for the anti-inflammatory activity and numerous compounds have been tested with this purpose in mind.

Although they display potent activity for the treatment of inflammation-related diseases, both steroidal and nonsteroidal anti-inflammatory drugs (NSAIDs) have been shown to cause various and severe side effects (32). Therefore, naturally occurring agents with very few side effects are suitable substitutes for chemical therapeutics $(12,16)$.

Previous studies by our research team have demonstrated the medicinal properties of the Agelanthus dodoneifolius (11). Here, we compared the effects of one of the traditional uses of Agelanthus dodoneifolius (i.e., the aqueous decoction to the diethyl ether, ethyl acetate and butanolic fractions of the plant) on the oxidant activity of activated neutrophils which results in the production of ROS and the release of MPO into the extracellular medium and on the activity of MPO having potent oxidant properties.

The formation of ROS was followed by chemiluminescence using the luminescent probe lucigenin because of its previously reported specificity toward superoxide anion $(24,25)$. All tested solutions demonstrated a remarkable dosedependent inhibitory effect on ROS production; the organic fractions were more potent than the aqueous extract. It is well known that the polyphenolic compounds of plants are highly effective free radical scavengers and antioxidants with potential biochemical and therapeutics effects (13). The organic fractions were richer in phenolics as determined by spectrophotometric methods; UPLC-MS/MS analysis allowed for the identification of some constituents of the fractions. These results suggested that the large inhibitory effect of the organic fractions on ROS production could be correlated with their phenolic content. In fact, polyphenolic compounds have antioxidant abilities in biological systems and may act as free radical scavengers in cells $(13,14)$. Moreover, they can interfere with the enzymatic activity of enzymes such as NADPH oxidase and the PKC. In fact, PKC has been implicated in the triggering of NADPH oxidase activation. $(2,13)$. Our chemiluminescence results suggest that the tested organic solutions in the concentration range of $0.5-50 \mu \mathrm{g} / \mathrm{ml}$ could interfere with the enzymatic activity of NADPH oxidase stimulated by PMA or could act as a direct scavenging agent on the oxidant products derived from stimulated neutrophils as the extract is always present during the neutrophil stimulation. Interestingly, in our model, gallic acid showed a better antioxidant activity than quercetin. This result may be due to their differences in lipophilicity, molecular size or the stimulus used for neutrophil activation. Gallic acid and quercetin were reported to demonstrate inhibitory activities on NADPH oxidase and scavenging effects on superoxide anions. They also have an ortho-dihydroxy catechol group (Fig. 1) which is a determinant of radical scavenging capability (33-35).

As neutrophils play an important role in the inflammatory response, inhibition of the degranulation process may play a role in their anti-inflammatory activity. The release of MPO by stimulated neutrophils is hypothesized to be an indication of neutrophil degranulation. Our results demonstrated that all tested extracts exerted a noticeable inhibitory effect on the MPO release by the PMA stimulated neutrophils and a significant response was obtained with the butanolic and ethyl acetate fractions. The greatest inhibitory activity obtained with the butanolic fraction could be correlated with high flavonoid content as determined by the $\mathrm{AlCl}_{3}$ colorimetric method. Rutin was the major component identified by the UPLC-MS/MS analysis. The mechanisms involved in neutrophil degranulation are dependent on several factors such as the PKC activation pathway, intracellular $\mathrm{Ca}^{2+}$ and the actin cytoskeleton. Jog et al (36) reported that the actin cytoskeleton restricts azurophil granule access to the plasma membrane under both basal and stimulated conditions to prevent the release of destructive enzymes such as myeloperoxidase. Studies have reported that some polyphenolic compounds, such as flavonoids, may disturb the degranulation process of the phagocytic cell by interacting with receptors on the cell membrane (37), inhibiting intracellular $\mathrm{Ca}^{2+}$ elevation via a reduction in phospholipase-C activity $(1,3)$ and by inhibiting PKC (by blocking the ATP binding site on the catalytic unit of PKC, for example) $(13,38,39)$. Ferriola et al $(39)$ showed that rutin, which differs from quercetin by the presence of the sugar rutinose, was less efficient at inhibiting PKC activity. However, Selloum et al (40) showed that rutin attained its anti-inflammatory properties by interfering with neutrophil chemotaxis and by partially inhibiting elastase exocytosis, 
probably by acting on the PI3-kinase and the mitogen-activated protein kinase (MAPK). Therefore, the inhibitory activity of the butanolic fraction on MPO release could be partly explained by the presence of rutin; however, further studies are needed to determine whether rutin alone could have such an effect on PMA-stimulated neutrophils. When compared with the inhibitory effects of gallic acid and quercetin, those effects of Agelanthus dodoneifolius extracts could be the result of the total activities of different compounds present in the fractions. Quercetin, which is known to disturb the degranulation pathway of neutrophils, demonstrated a poor effect in our neutrophil stimulation model. This result could be explained by the use of PMA as a stimulating agent, which acts directly on PKC activity and leads to the bypass of the previous events, such as tyrosine phosphorylation, phospholipase activation and signal transduction, which could be influenced by quercetin $(41,42)$.

Interestingly, evidence has emerged that MPO-derived oxidants contribute to tissue damage and to the initiation and propagation of acute and chronic vascular inflammatory diseases. Such evidence sparks considerable interest in the development of therapeutically useful MPO inhibitors including natural compounds (43). All tested extracts exerted a dose-dependent inhibitory effect on the specific activity of equine MPO as measured by the SIEFED assay. The SIEFED assay is a useful pharmacological tool to study specific inhibitors of MPO because there is no interference with the detection system by nonspecifically bound compounds or substances as they were washed before the MPO activity measurement. Inhibition of the enzyme can thus be explained by interactions of the tested extracts with the enzyme: these interactions include inducing conformational changes in the protein moiety and blocking or hindering the active site of the enzyme. The greatest inhibitory effect that was obtained with the ethyl acetate and diethyl ether fractions could be correlated with their high phenolic contents and better extraction of polyphenolic compounds. Several studies have reported that phenolic compounds such as gallic acid, curcumin, resveratrol and myricitrin are effective substrates and inhibitors of MPO $(8,9,44-46)$. In our study, we confirmed the inhibitory activities of gallic acid and quercetin. By using computer modelling, Shiba et al (46) suggested that quercetin and its glycoside dock at the active site of MPO, onto the hydrophobic region at the entrance to the distal heme pocket. This interaction leads to an inhibition such as seen with salicylhydroxamic acid a known MPO inhibitor. In fact, the presence of a pyrogallol group in the B ring of flavonoids (Fig. 1), of the 3-, 4-, and 5-OH, and of the C2-C3 double bond could improve the inhibitory effect $(45,46)$.

To our knowledge, this study is the first to measure the effect of the crude extracts or of the organic fractions from Agelanthus dodoneifolius in in vitro tests using stimulated neutrophils and purified equine MPO. We demonstrated the potent inhibitory effect of Agelanthus dodoneifolius extracts on ROS production, MPO release and the specific activity of MPO. A stronger effect was observed with the organic fractions than with the aqueous decoction already used in the folk medicine of Burkina Faso. Further studies will be carried out to isolate and identify all of the polyphenols present in the most active fraction. Taken together, our results demonstrate the interesting potential of Agelanthus fractions to modulate the inflammatory response by decreasing the oxidant response of neutrophils without causing any toxicity. Moreover, these findings provide a scientific basis for the traditional uses of Agelanthus dodoneifolius. One of these uses is related to the treatment of asthma, an allergic disease, which is also found in horses $(47,48)$. We can thus expect that this plant could have beneficial effects in the treatment of neutrophils-mediated inflammatory diseases.

\section{Acknowledgements}

The authors are most grateful for the encouragement and the facilities provided by Professor D. Serteyn, Center for Oxygen, Research and Development, Chemical Institute B6a, University of Liege, Belgium. This study was supported by grants (Ref: 4604/AMG/BE.BF. Project 9/VDL/doh/2007/ 22991) from the Wallonia-Brussels International (WBI). We gratefully thank Dr J. Hanson from the Department of Pharmaceutical Chemistry of the University of Liege for his help in using the GraphPad Prism software for estimation of the $\mathrm{IC}_{50}$ values. The SIEFED technique is protected by an international patent WO2005/075986 A2.

\section{References}

1. Russo-Marie F, Peltier A and Polla BS: L'inflammation. John Libbey Eurotext, Paris, 1998.

2. Zielinska-Przyjemska $\mathrm{M}$ and Wiktorowicz $\mathrm{K}$ : An in vitro study of the protective effect of the flavonoid silydianin against reactive oxygen species. Phytother Res 20: 115-119, 2006.

3. Borregaard N and Cowland JB: Granules of the human neutrophilic polymorphonuclear leukocytes. Blood 89: 3503-3521, 1997.

4. Klebanoff SJ: Myeloperoxidase: friend and foe. J Leukoc Biol 77: 598-625, 2005 .

5. Parke A and Parke DV: The pathogenesis of inflammatory disease: surgical shock and multiple system organ failure. Inflammopharmacology 3: 149-168, 1995.

6. Conforti F, Sosa S, Marrelli M, Menichini F, Statti GA, Uzunov D, Tubaro A, Menichini F and Loggia RD: In vivo antiinflammatory and in vitro antioxidant activities of Mediterranean dietary plants. J Ethnopharmacol 116: 144-151, 2008.

7. Deby-Dupont G, Deby C and Lamy M: Neutrophil myeloperoxidase revisited: its role in health and disease. Intensivmed Notfallmed 36: 500-513, 1999.

8. Kohnen S, Franck T, Van Antwerpen P, Boudjeltia KZ, Mouithys-Mickalad A, Deby C, Moguilevsky N, Deby-Dupont G, Lamy M and Serteyn D: Resveratrol inhibits the activity of equine neutrophil myeloperoxidase by a direct interaction with the enzyme. J Agric Food Chem 55: 8080-8087, 2007.

9. Franck T, Kohnen S, Grulke S, Neven P, Goutman Y, Peters F, Pirotte B, Deby-Dupont G and Serteyn D: Inhibitory effect of curcuminoids and tetrahydrocurcuminoids on equine activated neutrophils and myeloperoxidase activity. Physiol Res 57: 577-587, 2008.

10. Deeni YY and Sadiq NM: Antimicrobial properties and phytochemical constituents of leaves of African mistletoe (Tapinanthus dodoneifolius (DC) Danser) (Loranthaceae): an ethnomedicinal plant of Hausaland Northern Nigeria. J Ethnopharmacol 83: 235-240, 2002.

11. Ouedraogo M, Carreyre H, Vandebrouck C, Bescond J, Raymond G, Guissou IP, Cognard C, Becq F, Potreau D, Cousson A, Marrot J and Coustard JM: Structure elucidation of a dihydropyranone from Tapinanthus dodoneifolius. J Nat Prod 70: 2006-2009, 2007.

12. Adedapo AA, Sofidiya MO, Maphosa V, Moyo B, Masika PJ and Afolayan AJ: Anti-inflammatory and analgesic activities of the aqueous extract of Cussonia paniculata stem bark. Rec Nat Prod 2: 46-53, 2008.

13. Narayana KR, Reddy MS, Chaluvadi MR and Krishna DR: Bioflavonoids classification, pharmacological, biochemical effects and therapeutic potential. Indian J Pharmacol 33: 2-16, 2001. 
14. Duthie GG, Duthie SJ and Kyle JA: Plant polyphenols in cancer and heart disease: implications as nutritional antioxidants. Nutr Res Rev 13: 79-106, 2000.

15. Liu RH: Potential synergy of phytochemicals in cancer prevention: mechanism of action. J Nutr 134: 3479S-3485S, 2004.

16. Mule SN, Sandeep BP, Nilophar SN and Chandrakant SM Evaluation of antinociceptive and anti-inflammatory activity of stems of Gynandropsis pentaphylla Linn. Int J Green Pharm 2: 87-90, 2008.

17. Joo-Heon Y and Seung JB: Molecular targets of dietary polyphenols with anti-inflammatory properties. Yonsei Med J 46 585-596, 2005

18. De Rijke E, Out P, Niessen WM, Ariese F, Gooijer C and Brinkman UA: Analytical separation and detection methods for flavonoids. J Chromatogr A 1112: 31-63, 2006.

19. Foungbe S, Tillequin F, Paris M, Jacquemin H and Paris RR: Sur une pipéracée de Guyane, le Piper marginatum Jacq. Annal Pharm Fr 34: 339-343, 1976.

20. Kapasakalidis PG, Rastall RA and Gordon MH: Extraction of polyphenols from processed Black Currant (Ribes nigrum L.). J Agric Food Chem 54: 4016-4021, 2006

21. Franco D, Sineiro J, Rubilar M, Sanchez M, Jerez M, Pinelo M, Costoya $\mathrm{N}$ and Nunez MJ: Polyphenols from plant materials: extraction and antioxidant power. EJEAFche 7: 3210-3216, 2008.

22. Pycock JF, Allen WE and Morris TH: Rapid, single-step isolation of equine neutrophils on a discontinuous Percoll density gradient. Res Vet Sci 42: 411-412, 1987.

23. Benbarek H, Deby-Dupont G, Caudron I, Grulke S, Deby C, Lamy $M$ and Serteyn D: Interaction between lipopolysaccharides and blood factors on the stimulation of equine polymorphonuclear neutrophils. Vet Immunol Immunopathol 64: 313-322, 1998.

24. Van Dyke K, Patel S and Vallyathan V: Lucigenin chemiluminescence assay as an adjunctive tool for assessment of various stages of inflammation: a study of quiescent inflammatory cells. J Biosci 28: 115-119, 2003.

25. Qian Y, Cristol JP, Barnavon L, Riou C and Teissedre PL: Modulation of the NADPH oxidase in THP-1 derived monocytes by red-wine polyphenols extracts from Rhone valley wines. Bulletin de l'OIV 81: 231-240, 2008.

26. Franck T, Grulke S, Deby-Dupont G, Deby C, Duvivier H, Peters F and Serteyn D: Development of an enzyme-linked immunosorbent assay for specific equine neutrophil myeloperoxidase measurement in blood. J Vet Diagn Invest 17: 412-419, 2005

27. Franck T, Kohnen S, Deby-Dupont G, Grulke S, Deby C and Serteyn D: A specific method for measurement for equine active Myeloperoxidase in biological samples and in in vitro tests. J Vet Diagn Invest 18: 326-334, 2006.

28. Tsao R and Yang R: Optimization of a new mobile phase to know the complex and real polyphenolic composition: towards a total index using high-performance liquid chromatography. J Chromatogr A 1018: 29-40, 2003.

29. Singleton VL, Orthofer R and Lamuela-Raventos RM: Analysis of total phenols and other oxidation substrates and antioxidants by means of Folin-Ciocalteu reagent. Methods Enzymol 299: $152-178,1999$

30. Arvouet-Grand A, Vennat B, Pourrat A and Legret P: Standardisation d'un extrait de propolis et identification des principaux constituants. J Pharm Belg 49: 462-468, 1994.

31. Wright HL, Moots RJ, Bucknall RC and Edwards SW: Neutrophil function in inflammation and inflammatory diseases. Rheumatology 49: 1618-1631, 2010.
32. Ng SC: Non-steroidal anti-inflammatory drugs- uses and complications. Singapore Med J 33: 510-513, 1992.

33. Rice-Evans CA, Miller NJ and Paganga G: Structureantioxidant activity relationships of flavonoids and phenolic acids. Free Radic Biol Med 20: 933-956, 1996.

34. Krol W, Czuba Z, Scheller S, Paradowski Z and Shani J: Structure-activity relationship in the ability of flavonols to inhibit chemiluminescence. J Ethnopharmacol 41: 121-126, 1994.

35. Kroes BH, Van den Berg AJJ, Quarles van Ufford HC, Van Dijk $\mathrm{H}$ and Labadie RP: Anti-inflammatory activity of gallic acid. Planta Med 58: 499-504, 1992.

36. Jog NR, Rane MJ, Lominadze G, Luerman GC, Ward RA and McLeish KR: The actin cytoskeleton regulates exocytosis of all neutrophil granule subsets. Am J Physiol Cell Physiol 292: 1690-1700, 2007.

37. Kaneko M, Takimoto H, Sugiyama T, Seki Y, Kawaguchi K and Kumasawa Y: Suppressive effects of the flavonoids quercetin and luteolin on the accumulation of lipids raft after signal transduction via receptors. Immunopharmacol Immunotoxicol 30: 867-882, 2008 .

38. Middleton E Jr, Kandaswami C and Theoharides TC: The effects of plant flavonoids on mammalian cells: implications for inflammation, heart disease and cancer. Pharmacol Rev 52: 673-751, 2000 .

39. Ferriola PC, Cody V and Middleton E Jr: Protein kinase C inhibition by plant flavonoids: kinetic mechanisms and structureactivity relationships. Biochem Pharmacol 38: 1617-1624, 1989.

40. Selloum L, Bourich H, Tigrine C and Boudoukha C: Antiinflammatory effects of rutin on rat paw oedema and on neutrophils chemotaxis and degranulation. Exp Toxicol Pathol 54: 313-318, 2003

41. Takemura OS, Banno $Y$ and Nozawa $Y$ : Inhibition of Nformylmethionyl-leucyl-phenylalanine-stimulated tyrosine phosphorylation and phospholipase $\mathrm{D}$ activation by quercetin in rabbits neutrophils. Biochem Pharmacol 53: 1503-1510, 1997.

42. Liu JJ, Song CW, Yue Y, Duan CG, Yang J, He T and He YZ: Quercetin inhibits LPS-induced delay in spontaneous apoptosis and activation of neutrophils. Inflamm Res 54: 500-507, 2005.

43. Malle E, Furtmuller PG, Sattler W and Obinger C: Myeloperoxidase: a target for new drug development? Br J Pharmacol 152: 838-854, 2007.

44. Kato Y, Nagao A, Terao J and Osawa T: Inhibition of myeloperoxidase-catalysed tyrosylation by phenolic antioxidants in vitro. Biosci Biotechnol Biochem 67: 1136-1139, 2003.

45. Meotti FC, Senthilmohan R, Harwood DT, Missau FC, Pizzolatti MG and Kettle AJ: Myricitrin as a substrate and inhibitor of myeloperoxidase: implications for the pharmacological effects of flavonoids. Free Radic Biol Med 44: 109-120, 2008.

46. Shiba Y, Kinoshita T, Chuman H, Taketani Y, Takeda E, Kato Y, Naito M, Kawabata, K, Ishisaka A, Terao J and KawaiY: Flavonoids as substrates and inhibitors of myeloperoxidase: molecular actions of aglycone and metabolites. Chem Res Toxicol 21: 1600-1609, 2008 .

47. Art T, Franck T, Lekeux P, De Moffarts B, Couetil L, Becker M, Kohnen S, Deby-Dupont G and Serteyn D: Myeloperoxidase concentration in brochoalveolar lavage fluid from healthy horses and those with recurrent airway obstruction. Can J Vet Res 70: 291-296, 2006

48. Verwilghen D, Busoni V, Gangl M, Franck T, Lejeune JP Vanderheyden L, Detilleux J, Grulke S, Deberg M, Henrotin Y and Serteyn D: Relationship between biochemical markers and radiographic scores in the evaluation of the osteoarticular status of warmblood stallions. Res Vet Sci 87: 319-328, 2009. 